\title{
ХАРАКТЕР МОЛЕКУЛЯРНОЙ ЭВОЛЮЦИИ МИТОХОНДРИАЛЬНЫХ ГЕНОМОВ РУССКОГО НАСЕЛЕНИЯ ВОСТОЧНОЙ ЕВРОПЫ
}

\author{
Литвинов А. Н., Малярчук Б. А., Деренко М. В. \\ ФГБУН Институт биологических проблем Севера ДВО РАН, г. Магадан \\ E-mail: malyarchuk@ibpn.ru
}

\begin{abstract}
Исследована роль естественного отбора в эволюции митохондриальных геномов популяций русского населения Восточной Европы, а также других европейских народов (поволжских татар, эстонцев, поляков, венгров, сербов), для которых имеются популяционные наборы данных об изменчивости целых митохондриальных геномов. Установлено, что отбор не оказывает существенного влияния на митохондриальные геномы русского населения, однако анализ отдельных генов позволил выявить влияние положительного отбора на ген $N D 3$. Результаты анализа объединенной выборки митохондриальных геномов населения Европы свидетельствуют о том, что отрицательный отбор является основным селективным фактором, воздействующим как на митохондриальные генофонды в целом, так и на отдельные митохондриальные гены европейцев (гены $N D 1$ и CO2).
\end{abstract}

Ключевые слова: митохондриальная ДНК, русские популяции, генетический полиморфизм, естественный отбор.

DOI: $10.34078 / 1814-0998-2020-2-107-113$

Митохондриальная ДНК (мтДНК) человека наследуется по материнской линии и без рекомбинации, характеризуется высоким числом копий в митохондриях и повышенной (в 5-10 раз в сравнении с ядерным геномом) скоростью накопления мутаций (Giles et al., 1980; Brown et al., 1982). Так, согласно современным данным, скорость накопления мутаций в митохондриальном геноме человека составляет $1.6 \cdot 10^{-8}$ замен на нуклеотидную позицию в год (Soares et al., 2009), а в ядерном геноме человека $-0.6 \cdot 10^{-9}$ замен на нуклеотидную позицию в год (Lipson et al., 2015). Благодаря указанным свойствам мтДНК стала важнейшим инструментом для изучения генетического разнообразия в популяциях человека на протяжении последних 40 лет (Brown et al., 1979). Между тем вопрос о характере изменчивости митохондриальных геномов является не до конца изученным, поскольку лишь в начале 2000-х гг. появились популяционные данные об изменчивости целых молекул мтДНК (Mishmar et al., 2003; Elson et al., 2004). Результаты такого рода исследований показали, что митохондриальные геномы находятся под воздействием отрицательного (или очищающего) отбора. При этом мутационные спектры мтДНК характеризуются выраженным преобладанием синонимичных 2020

(C) Литвинов А. Н., Малярчук Б. А., Деренко М. В., нуклеотидных замен, не приводящих к заменам аминокислот в белках, над несинонимичными заменами, которые приводят к аминокислотным заменам (Moilanen, Majamaa, 2003; Elson et al., 2004; Kivisild et al., 2006; Деренко, Малярчук, 2010). Такая особенность эволюции мтДНК может объясняться функциональной важностью и, следовательно, консервативностью белков, кодируемых митохондриальным геномом, поскольку митохондрии отвечают в клетке за одну из важнейших функций - производство энергии в форме АТФ.

Между тем некоторые исследователи отмечали, что селективное давление различается в разных генах мтДНК, что может быть следствием адаптации популяций человека к условиям природной среды, в которой они проживают (Mishmar et al., 2003; Ruiz-Pesini et al., 2004; Ельцов и др., 2010). Такого рода выводы следуют из факта обнаружения ослабления отрицательного отбора в некоторых генах мтДНК в популяциях, населяющих различные природно-климатические зоны: в гене ATP6 в популяциях арктической зоны, в гене $C Y T B$ - в популяциях умеренной зоны и генах $C O 1$ и $N D 3$ - в тропических популяциях (Mishmar et al., 2003; Ingman, Gyllensten, 2007).

Однако другие исследования показали, что различия по числу несинонимичных замен в различных генах мтДНК связаны не с климатическими условиями, а с эволюционным возрастом 
митохондриальных гаплогрупп, т. е. филогенетически родственых гаплотипов мтДНК (Moilanen, Majamaa, 2003; Elson et al., 2004; Kivisild et al., 2006; Деренко, Малярчук, 2010; Малярчук, 2011). В данном случае предполагается, что синонимичные и несинонимичные замены распределены по митохондриальному филогенетическому дереву неравномерно: количество несинонимичных замен в эволюционно «молодых» концевых ветвях мтДНК выше, чем в более древних «стволах» филогенетического дерева. Таким образом, отрицательный отбор, направленный на стабилизацию структуры митохондриальных генов, действует на всех стадиях эволюции мтДНК, но чем ближе к настоящему времени, тем выше частота несинонимичных замен, которые еще не успели пройти все стадии отрицательного отбора (Elson et al., 2004; Kivisild et al., 2006; Малярчук, 2011).

Предыдущие исследования характера эволюции митохондриальных геномов европейцев показали, что при изучении митохондриальных генофондов популяций отбор может быть зарегистрирован на уровне как отдельных генов мтДНК, так и гаплогрупп мтДНК (Moilanen et al., 2003; Elson et al., 2004; Малярчук, 2011). Однако лишь в настоящее время после опубликования большого массива данных об изменчивости целых митохондриальных геномов русского населения Восточной Европы (Malyarchuk et al., 2017 ) появляется возможность для более детального анализа характера изменчивости митохондриальных геномов. Данный аспект является целью настоящей работы.

\section{МАТЕРИАЛ И МЕТОДЫ}

Проанализированы ранее опубликованные данные об изменчивости целых митохондриальных геномов в шести популяциях русского населения Восточной Европы (суммарно 376 митогеномов): Белгородской, Орловской, Тульской, Владимирской, Псковской и Новгородской областей (Malyarchuk et al., 2017).

Показатели генетического разнообразия мтДНК рассчитаны с помощью пакета программ DnaSP v.5 (Librado, Rozas, 2009). Тестирование нейтральности мутационного процесса в митогеномах проводили с помощью теста Таджимы, peализованного в пакете программ DnaSP v.5.

Для расчета $\mathrm{Ka} / \mathrm{Ks}$ - соотношения числа несинонимичных замен на несинонимичный сайт (Ка) к числу синонимичных замен на синонимичный сайт (Ks), использовали программы пакета DnaSP v.5. Общее число синонимичных и несинонимичных сайтов рассчитывали с помощью метода эволюционных путей (Nei, Gojobori, 1986). Предполагается действие отрицательного отбора при $\mathrm{Ka} / \mathrm{Ks}<1$ и положительного отбора при $\mathrm{Ka} / \mathrm{Ks}>1$.
Для исследования влияния отбора на распределение мутаций в генах мтДНК использовали статистический тест, описанный в работе (Elson et al., 2004) и реализованный в программе mtPhyl v. 4.015 (http://eltsov.org/mtphyl). Анализ основывается на сравнении значений соотношений несинонимичных (NS) и синонимичных (S) замен в группах кластер-специфичных замен (H), ассоциированных со «стволами» филогенетических кластеров, и уникальных замен в отдельных концевых ветвях митохондриального дерева (Р). Индекс нейтральности (NI) рассчитывали как $\left(\mathrm{NS}_{\mathrm{P}} /\right.$ $\left.\mathrm{S}_{\mathrm{P}}\right) /\left(\mathrm{NS}_{\mathrm{H}} / \mathrm{S}_{\mathrm{H}}\right)$. Предполагается, что в отсутствие отбора индекс нейтральности NI принимает значения, близкие к 1.0 ; когда NI > 1 , то ожидается действие отрицательного отбора, а когда NI $<1$, то действие положительного отбора.

\section{РЕЗУЛЬТАТЫ И ОБСУЖДЕНИЕ}

Анализ данных о полногеномной изменчивости мтДНК у русского населения Восточной Европы в сравнении с другими европейскими популяциями показывает, что русские занимают промежуточное положение среди европейцев. Нуклеотидное разнообразие у русских выше, чем, например, у сардинцев, эстонцев и сербов, но ниже, чем у поляков, поволжских татар, тосканцев и венгров (табл. 1). При сопоставлении русских, сгруппированных по территориальному принципу, т. е. при сравнении популяций СевероЗападного региона (Псковская и Новгородская области) с популяциями более южных областей (Белгородская, Орловская, Тульская и Владимирская области), выявляются очень небольшие различия. Так, у северо-западных русских нуклеотидное разнообразие $\mathrm{Pi}=0.0016$, а у более южных русских $-\mathrm{Pi}=0.0018$, что вполне соответствует уровню европейских межпопуляционных различий, показанных в табл. 1 .

Результаты тестирования нейтральности эволюции мтДНК с помощью теста Таджимы показывают, что параметр Tajima's D для митохондриальных генофондов русских, а также других европейских популяций имеет значимо отрицательные значения, что свидетельствует о воздействии отрицательного отбора на эволюцию мтДНК (см. табл. 1). Значения соотношений $\mathrm{Ka} / \mathrm{Ks}$ для всех митохондриальных генов у русских не превышают 1 (суммарно для всех белоккодирующих генов $\mathrm{Ka} / \mathrm{Ks}=0.195)$, что также предполагает воздействие отрицательного отбора (см. рисунок). Наиболее высокие значения $\mathrm{Ka} /$ $\mathrm{Ks}$ (более 0.3) наблюдаются в генах ATP6, ATP8 и $C Y T B$ (см. рисунок). Отметим, что аналогичные результаты были получены и в других исследованиях популяций человека (Mishmar et al., 2003; Moilanen, Majamaa, 2003; Elson et al., 2004; Ingman, Gyllensten, 2007). 
Таблища 1. Генетическое разнообразие и результаты тестирования на нейтральность изменчивости мтДНК в исследованных популяциях

Table 1. Genetic diversity and results of testing for mtDNA variability neutrality in the studied populations

\begin{tabular}{|l|c|c|c|c|c|c|c|}
\hline \multicolumn{1}{|c|}{ Популяция } & $\mathrm{N}$ & $\mathrm{S}$ & $\mathrm{H}$ & $\mathrm{Hd}$ & $\mathrm{Pi}$ & $\mathrm{k}$ & Tajima's D $(p)$ \\
\hline Русские $^{1}$ & 376 & 1097 & 361 & $1 \pm 0$ & $0.0018 \pm 0.0001$ & 29.02 & $-2.57(<0.001)$ \\
\hline Поляки $^{1}$ & 100 & 582 & 97 & $0.99 \pm 0.002$ & $0.002 \pm 0.0001$ & 32.48 & $-2.43(<0.01)$ \\
\hline Эстонцы $^{2}$ & 119 & 481 & 106 & $0.99 \pm 0.001$ & $0.0017 \pm 0.0001$ & 27.93 & $-2.33(<0.01)$ \\
\hline Поволжские татары $^{3}$ & 73 & 507 & 68 & $0.99 \pm 0.003$ & $0.0021 \pm 0.0001$ & 35.2 & $-2.33(<0.01)$ \\
\hline Тосканцы $^{4}$ & 110 & 685 & 109 & $1 \pm 0.003$ & $0.0019 \pm 0.0001$ & 30.68 & $-2.58(<0.001)$ \\
\hline Сербы $^{5}$ & 165 & 687 & 152 & $0.99 \pm 0.001$ & $0.0016 \pm 0.0001$ & 27.12 & $-2.54(<0.001)$ \\
\hline Венгры $^{6}$ & 80 & 457 & 78 & $1 \pm 0.002$ & $0.0018 \pm 0.0001$ & 29.82 & $-2.36(<0.01)$ \\
\hline Сардинцы $^{7}$ & 63 & 234 & 50 & $0.99 \pm 0.004$ & $0.0015 \pm 0.0001$ & 24.31 & $-1.8(<0.05)$ \\
\hline
\end{tabular}

Примечание. N - размер выборки; S - число полиморфных сайтов; Н - количество выявленных гаплотипов; Нd гаплотипическое разнообразие и стандартное отклонение; Рi - нуклеотидное разнообразие и стандартное отклонение; $\mathrm{k}-$ среднее число попарных нуклеотидных различий; Тајіma's D - результат теста на нейтральность Таджимы и статистическая значимость. 1 - по данным работы (Malyarchuk et al., 2017); 2 - по данным работы (Stoljarova et al., 2016); 3 - по данным работы (Malyarchuk et al., 2010); 4 - по данным проекта 1000 Genomes Project (http://www.internationalgenome.org); 5 - по данным работы (Kovacevic-Grujicic et al., 2018); 6 - по данным работы (Malyarchuk et al., 2018); 7 - по данным работы (Fraumene et al., 2006).

Рис. Распределение значений показателя $\mathrm{Ka} / \mathrm{Ks}$ в белоккодирующих генах митохондриального генома у русских. По оси $\mathrm{X}$ показаны гены мтДНК в том порядке, в каком они расположены на митохондриальном геноме, по оси Y - значение показателя $\mathrm{Ka} / \mathrm{Ks}$

Fig. Distribution of $\mathrm{Ka} / \mathrm{Ks}$ values in the protein-coding genes of the mitochondrial genome in Russians. The $\mathrm{X}$-axis shows the mtDNA genes in the order they are located on the mitochondrial genome; the Yaxis, the $\mathrm{Ka} / \mathrm{Ks}$ values

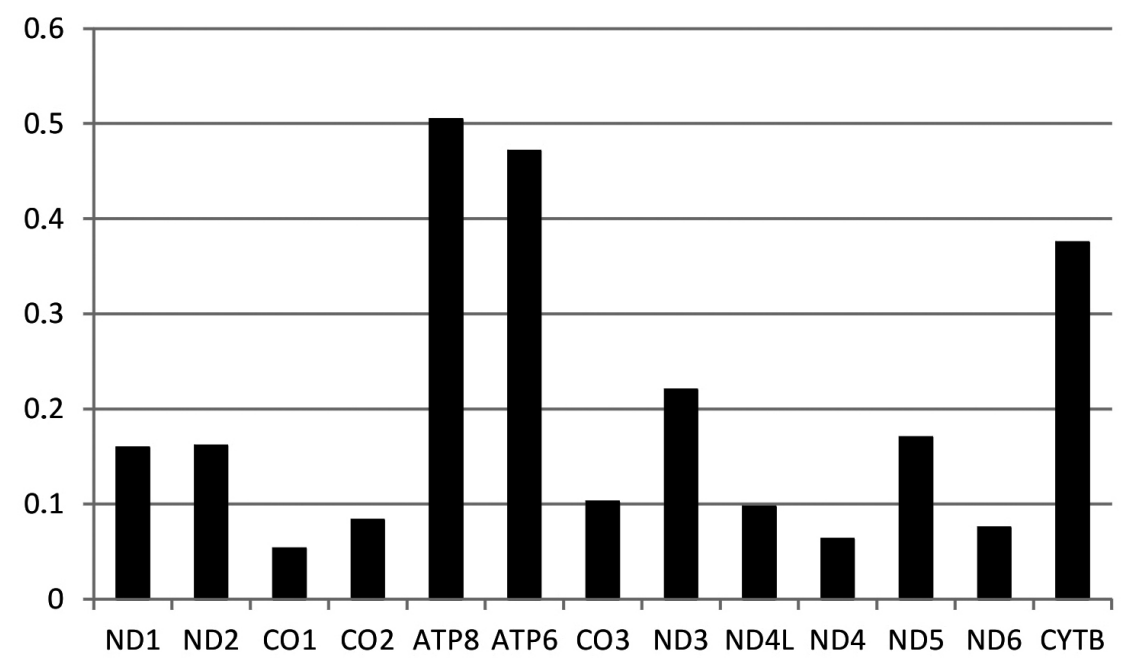

Для исследования влияния естественного отбора на характер распределения мутаций в генах мтДНК нами использован также статистический подход, описанный в работе (Elson et al., 2004). Этот тест основывается на сравнении значений соотношений несинонимичных и синонимичных нуклеотидных замен в «стволах» и «концевых ветвях» филогенетических кластеров митохондриального дерева. Анализ митохондриальных генофондов русских, а также других европейских популяций показал, что значения индекса нейтральности NI находятся вблизи 1.0, а значения соотношений несинонимичных и синонимичных замен статистически достоверно не различаются, что свидетельствует об отсутствии влияния отбора на полиморфизм мтДНК в отдельных европейских популяциях (табл. 2).

Между тем анализ распределения нуклеотидных замен в генах мтДНК у русских пока- зал наличие статистически значимых отклонений значений индекса нейтральности NI от единицы только в одном случае: в гене ND3 (NI = $0.12, \mathrm{P}=0.01)$ у русских выявлен положительный отбор (табл. 3). При сравнении русских популяций Северо-Западного региона и более южных областей (Белгородская, Орловская, Тульская и Владимирская области) эта же тенденция, т. е. положительный отбор в гене ND3 сохраняется только в более южных популяциях $(\mathrm{NI}=0.14, \mathrm{P}=0.02)$. Анализ митохондриальных генофондов других европейских популяций (эстонцев, венгров, сербов, поляков и поволжских татар) показал, что только в одной популяции - у поволжских татар, наблюдается отклонение от нейтральности и тоже только в гене $N D 3(\mathrm{NI}=0.08, \mathrm{P}=0.045)$. Положительный отбор, выявленный в гене ND3 у русских и татар, связан с преобладанием несинонимичных замен в «стволах» филогенетических кла- 
Таблица 2. Анализ распределения несинонимичных (NS) и синонимичных (S) замен в митохондриальных генофондах популяций Европы (тест Elson et al., 2004)

Table 2. Analysis of distribution of nonsynonymous (NS) and synonymous (S) substitutions in the mitochondrial gene pools of European populations (test from Elson et al., 2004)

\begin{tabular}{|c|c|c|c|c|c|c|c|c|}
\hline \multirow{2}{*}{ Популяция } & \multicolumn{3}{|c|}{$\begin{array}{l}\text { Количество замен, ассоцированных } \\
\text { с гаплогруппами } \\
\end{array}$} & \multicolumn{3}{|c|}{ Количество уникальных замен } & \multirow[t]{2}{*}{$\mathrm{P}$} & \multirow[t]{2}{*}{ NI } \\
\hline & NS & $\mathrm{S}$ & $\mathrm{NS} / \mathrm{S}$ & NS & $\mathrm{S}$ & $\mathrm{NS} / \mathrm{S}$ & & \\
\hline Русские & 98 & 217 & 0.45 & 221 & 412 & 0.54 & 0.274 & 1.19 \\
\hline Поляки & 32 & 69 & 0.46 & 96 & 221 & 0.43 & 0.805 & 0.94 \\
\hline Эстонцы & 43 & 87 & 0.49 & 73 & 137 & 0.53 & 0.814 & 1.08 \\
\hline Поволжские татары & 37 & 74 & 0.5 & 82 & 147 & 0.47 & 0.809 & 0.94 \\
\hline Сербы & 38 & 66 & 0.58 & 63 & 123 & 0.51 & 0.7 & 0.89 \\
\hline Венгры & 36 & 70 & 0.51 & 74 & 146 & 0.51 & 1.0 & 0.99 \\
\hline
\end{tabular}

Примечание. Достоверность различий (Р) определяли с помощью двустороннего точного теста Фишера. NI - индекс нейтральности. В отсутствие отбора NI $\sim 1.0$; когда $\mathrm{NI}>1.0$, то ожидается действие отрицательного отбора, а когда NI $<1.0$, то действие положительного отбора.

Таблица 3. Анализ распределения несинонимичных (NS) и синонимичных (S) замен в митохондриальном генофонде русского населения Восточной Европы (тест Elson et al., 2004)

Table 3. Analysis of distribution of nonsynonymous (NS) and synonymous (S) substitutions in the mitochondrial gene pool of the Russian population in East Europe (test Elson et al., 2004)

\begin{tabular}{|l|c|c|c|c|c|c|c|c|}
\hline \multirow{2}{*}{ Ген } & \multicolumn{2}{|c|}{ Количество замен, ассоцированных с гаплогруппами } & \multicolumn{2}{|c|}{ Количество уникальных замен } & \multirow{2}{*}{ P } & \multirow{2}{*}{ NI } \\
\cline { 2 - 7 } & $\mathrm{NS}$ & $\mathrm{S}$ & $\mathrm{NS} / \mathrm{S}$ & $\mathrm{NS}$ & $\mathrm{S}$ & $\mathrm{NS} / \mathrm{S}$ & & 1 \\
\hline ND1 & 6 & 23 & 0.26 & 11 & 40 & 0.28 & 1.05 \\
\hline ND2 & 13 & 22 & 0.59 & 17 & 42 & 0.4 & 0.494 & 0.68 \\
\hline CO1 & 7 & 25 & 0.28 & 15 & 57 & 0.26 & 1 & 0.94 \\
\hline CO2 & 1 & 13 & 0.08 & 11 & 22 & 0.5 & 0.077 & 6.5 \\
\hline ATP8 & 3 & 3 & 1 & 9 & 5 & 1.8 & 0.642 & 1.8 \\
\hline ATP6 & 18 & 13 & 1.38 & 38 & 20 & 1.9 & 0.5 & 1.37 \\
\hline CO3 & 6 & 14 & 0.43 & 8 & 21 & 0.38 & 1 & 0.89 \\
\hline ND3 & $\mathbf{8}$ & $\mathbf{5}$ & $\mathbf{1 . 6}$ & $\mathbf{4}$ & $\mathbf{2 0}$ & $\mathbf{0 . 2}$ & $\mathbf{0 . 0 1}$ & $\mathbf{0 . 1 2}$ \\
\hline ND4L & 0 & 8 & 0 & 5 & 10 & 0.5 & 0.091 & 0 \\
\hline ND4 & 3 & 26 & 0.12 & 15 & 42 & 0.36 & 0.1 & 3.1 \\
\hline ND5 & 22 & 37 & 0.59 & 41 & 79 & 0.52 & 0.74 & 0.87 \\
\hline ND6 & 1 & 12 & 0.08 & 9 & 18 & 0.5 & 0.124 & 6 \\
\hline CYTB & 10 & 16 & 0.62 & 38 & 36 & 1.06 & 0.267 & 1.69 \\
\hline
\end{tabular}

Примечание. Обозначения, как в табл. 2. Достоверные значения NI показаны полужирным шрифтом.

стеров - в 1.6 раза в случае митогеномов русского населения (см. табл. 3). Для выяснения причин этого необходимы дополнительные исследования.

Анализ совокупного митохондриального генофонда европейцев, представленных русскими, эстонцами, венграми, сербами, поляками и поволжскими татарами $(\mathrm{N}=919)$, показывает наличие статистически значимого отрицательного отбора, действующего как в отдельных генах $(N D 1, C O 2)$, так во всей совокупности митохондриальных генов (табл. 4). Отметим, что в проведенном ранее исследовании (Elson et al., 2004) также было выявлено воздействие отрицательного отбора как на совокупность белоккодирующих митохондриальных генов, так и на отдельные гены (CO1, ND4 и ND6). Однако в работе (Elson et al., 2004) анализировалась смешанная в этнорасовом отношении выборка, представленная европейцами, азиатами и африканцами $(\mathrm{N}=560)$.

Таким образом, полученные результаты свидетельствуют о том, что в случае анализа всей совокупности белок-кодирующих генов естественный отбор не оказывает существенного влияния на митохондриальный генофонд русского населения Восточной Европы, однако анализ отдельных генов свидетельствует о воздействии положительного отбора на ген $N D 3$.

Между тем результаты анализа объединенной выборки митохондриальных геномов населения Европы определенно указывают на отрицательный отбор как основной селективный фактор, действующий как на митохондриальные генофонды в целом, так и на отдельные митохондриальные гены. 
Таблища 4. Анализ распределения несинонимичных (NS) и синонимичных (S) замен в митохондриальном генофонде европейцев (тест Elson et al., 2004)

Table 4. Analysis of distribution of nonsynonymous (NS) and synonymous (S) substitutions in the European mitochondrial gene pool (test from Elson et al., 2004)

\begin{tabular}{|c|c|c|c|c|c|c|c|c|}
\hline \multirow[t]{2}{*}{ Ген } & \multicolumn{3}{|c|}{$\begin{array}{c}\text { Количество замен, ассоцированных } \\
\text { с гаплогруппами } \\
\end{array}$} & \multicolumn{3}{|c|}{ Количество уникальных замен } & \multirow[t]{2}{*}{$\mathrm{P}$} & \multirow[t]{2}{*}{ NI } \\
\hline & $\mathrm{NS}$ & $\mathrm{S}$ & $\mathrm{NS} / \mathrm{S}$ & $\mathrm{NS}$ & $\mathrm{S}$ & $\mathrm{NS} / \mathrm{S}$ & & \\
\hline ND1 & 9 & 41 & 0.22 & 40 & 65 & 0.62 & 0.016 & 2.8 \\
\hline ND2 & 23 & 35 & 0.66 & 27 & 76 & 0.36 & 0.11 & 0.54 \\
\hline $\mathrm{CO1}$ & 10 & 53 & 0.19 & 38 & 99 & 0.38 & 0.076 & 2.03 \\
\hline $\mathrm{CO} 2$ & 2 & 24 & 0.08 & 24 & 46 & 0.52 & 0.009 & 6.26 \\
\hline ATP8 & 10 & 5 & 2 & 12 & 20 & 0.6 & 0.116 & 0.3 \\
\hline ATP6 & 27 & 19 & 1.42 & 80 & 37 & 2.16 & 0.274 & 1.52 \\
\hline $\mathrm{CO} 3$ & 9 & 23 & 0.39 & 29 & 46 & 0.63 & 0.379 & 1.61 \\
\hline ND3 & 12 & 14 & 0.86 & 11 & 28 & 0.39 & 0.187 & 0.46 \\
\hline ND4L & 3 & 13 & 0.23 & 3 & 12 & 0.25 & 1 & 1.08 \\
\hline ND4 & 8 & 58 & 0.14 & 33 & 109 & 0.3 & 0.064 & 2.19 \\
\hline ND5 & 42 & 75 & 0.56 & 67 & 144 & 0.47 & 0.465 & 0.83 \\
\hline ND6 & 5 & 20 & 0.25 & 16 & 47 & 0.34 & 0.783 & 1.36 \\
\hline CYTB & 25 & 40 & 0.62 & 65 & 65 & 1 & 0.087 & 1.6 \\
\hline Все гены & 185 & 420 & 0.44 & 445 & 794 & 0.56 & 0.025 & 1.27 \\
\hline
\end{tabular}

Примечание. Обозначения, как в табл. 3.

Дальнейшие исследования могут быть направлены на выяснение причин различий в направленности и силе действия отбора в эволюции мтДНК человека.

\section{ЛИТЕРАТУРА}

Деренко М. В., Малярчук Б. А. Молекулярная филогеография населения Северной Евразии по данным об изменчивости митохондриальной ДНК. Магадан : СВНЦ ДВО РАН, 2010. $376 \mathrm{c.}$

Ельичов Н. П., Володько Н. В., Стариковская Е. Б., Мазунин И. О., Сукерник Р. И. Роль естественного отбора в эволюции митохондриальных гаплогрупп Северо-Восточной Евразии // Генетика. 2010. Т. 46, № 9. С. 1247-1249.

Малярчук Б. А. Сигналы адаптивной эволюции митохондриальных генов у европейцев // Биохимия. 2011. T. 76, № 6. С. 858-863.

Brown W. M., Prager E. M., Wang A., Wilson A. C. Mitochondrial DNA sequences of primates: tempo and mode of evolution // J. Mol. Evol. 1982. Vol. 18. P. 225-239.

Brown W. M., George M. Jr., Wilson A. C. Rapid evolution of animal mitochondrial DNA // Proc. Natl. Acad. Sci. USA. 1979. Vol. 76. P. 1967-1971.

Elson J. L., Turnbull D. M., Howell N. Comparative genomics and the evolution of human mitochondrial DNA: assessing the effects of selection // Am. J. Hum. Genet. 2004. Vol. 74. P. 229-238.

Fraumene C., Belle E. M., Castri L., Sanna S., Mancosu G., Cosso M., Marras F., Barbujani G., Pirastu M., Angius $A$. High resolution analysis and phylogenetic network construction using complete mtDNA sequences in Sardinian genetic isolates // Mol. Biol. Evol. 2006. Vol. 23. P. 2101-2111.

Giles R. E., Blanc H., Cann H. M., Wallace D. C. Maternal inheritance of human mitochondrial DNA //
Proc. Natl. Acad. Sci. USA. 1980. Vol. 77. P. 67156719.

Ingman M., Gyllensten $U$. Rate variation between mitochondrial domains and adaptive evolution in humans // Hum. Mol. Genet. 2007. Vol. 16. P. 2281-2287.

Kivisild T., Shen P., Wall D. P., Do B., Sung R., Davis K., Passarino G., Underhill P. A., Scharfe C., Torroni A., Scozzari R., Modiano D., Coppa A., de Knijff P., Feldman M., Cavalli-Sforza L. L., Oefner P. J. The role of selection in the evolution of human mitochondrial genomes // Genetics. 2006. Vol. 172. P. 373-387.

Kovacevic-Grujicic N., Davidovic S., Malyarchuk B., Aleksic J., Grzybowski T., Derenko M., Litvinov A., Stevanovic $M$. Insights into the mitochondrial gene pool of Serbian population: phylogenetic and phylogeographic analysis // Biologia Serbica. 2018. Vol. 40, No. 1 (Special Edition). P. 36.

Librado P., Rozas J. DnaSP v5: a software for comprehensive analysis of DNA polymorphism data // Bioinformatics. 2009. Vol. 25. P. 1451-1452.

Lipson M., Loh P.-R., Sankararaman S., Patterson N., Berger B., Reich D. Calibrating the human mutation rate via ancestral recombination density in diploid genomes // PLoS Genet. 2015. Vol. 11. e1005550.

Malyarchuk B., Litvinov A., Derenko M., Skonieczna K., Grzybowski T., Grosheva A., Shneider Y., Rychkov S., Zhukova O. Mitogenomic diversity in Russians and Poles // Forensic Science International: Genetics. 2017. Vol. 30. P. 51-56.

Malyarchuk B., Derenko M., Denisova G., Kravtsova $O$. Mitogenomic diversity in Tatars from the VolgaUral region of Russia // Mol. Biol. Evol. 2010. Vol. 27. P. 2220-2226.

Malyarchuk B., Derenko M., Denisova G., Litvinov A., Rogalla U., Skonieczna K., Grzybowski T., Pentelényi K., Molnár M. J., Guba Z., Zeke T. Whole mitochondrial genome diversity in two Hungarian populations // 
Molecular Genetics and Genomics. 2018. Vol. 293. P. 1255-1263.

Mishmar D., Ruiz-Pesini E., Golik P., Macaulay V., Clark A. G., Hosseini S., Brandon M., Easley K., Chen E., Brown M. D., Sukernik R. I., Olckers A., Wallace D. C. Natural selection shaped regional mtDNA variation in humans // Proc. Natl. Acad. Sci. USA. 2003. Vol. 100. P. 171-176.

Moilanen J. S., Finnila S., Majamaa K. Lineagespecific selection in human mtDNA: lack of polymorphisms in a segment of MTND5 gene in haplogroup $\mathrm{J} / /$ Mol. Biol. Evol. 2003. Vol. 20. P. 2132-2142.

Moilanen J. S., Majamaa K. Phylogenetic network and physicochemical properties of nonsynonymous mutations in the protein-coding genes of human mitochondrial DNA// Ibid. 2003. Vol. 20. P. 1195-1210.
Nei M., Gojobori T. Simple methods for estimating the numbers of synonymous and nonsynonymous nucleotide substitutions // Mol. Biol. Evol. 1986. Vol. 3. P. 418-426.

Ruiz-Pesini E., Mishmar D., Brandon M., Procaccio V., Wallace D. C. Effects of purifying and adaptive selection on regional variation in human mtDNA // Science. 2004. Vol. 303. P. 223-226.

Soares P., Ermini L., Thomson N., Normina M., Rito T., Rohl A., Salas A., Oppenheimer S., Macaulay V., Richards $M$. B. Correcting for purifying selection: an improved human mitochondrial molecular clock // Am. J. Hum. Genet. 2009. Vol. 84. P. 740-759.

Stoljarova M., King J. L., Takahashi M., Aaspõllu A., Budowle B. Whole mitochondrial genome genetic diversity in an Estonian population sample // Int. J. Legal Med. 2016. Vol. 130. P. 67-71.

Поступила в редакиию 06.02.2019 2.

Поступила после доработки 01.07.2019 2.

\title{
THE NATURE OF THE MOLECULAR EVOLUTION OF THE MITOCHONDRIAL GENOMES OF THE RUSSIAN POPULATION OF EAST EUROPE
}

\author{
A. N. Litvinov, B. A. Malyarchuk, M. V. Derenko \\ Institute of Biological Problems of the North, FEB RAS, Magadan
}

\begin{abstract}
The role of natural selection in the mitochondrial genome evolution in Russian populations of East Europe as well as in other European populations (Volga Tatars, Estonians, Poles, Hungarians, Serbs), for whom population data sets on the variability of complete mitochondrial genomes are available. It has been found that selection does not affect the mitochondrial genomes of the Russians, but the individual gene analysis shows the effect of positive selection on the ND3 gene. The results of the analysis of a combined sample of Europeans' mitochondrial genomes indicate that negative selection is the main selective factor affecting both the mitochondrial gene pools in general and individual mitochondrial genes of Europeans ( $N D 1$ and $\mathrm{CO} 2$ genes).
\end{abstract}

Keywords: mitochondrial DNA, Russian populations, genetic polymorphism, natural selection.

\section{REFERENCES}

Brown, W. M.; George, M. Jr.; Wilson, A. C., 1979, Rapid Evolution of Animal Mitochondrial DNA, Proc. Natl. Acad. Sci. USA, 76, 1967-1971.

Brown, W. M.; Prager, E. M.; Wang, A.; Wilson, A. C., 1982, Mitochondrial DNA Sequences of Primates: Tempo and Mode of Evolution, J. Mol. Evol., 18, 225-239.

Derenko, M. V.; Malyarchuk, B. A., 2010, Molecular Phylogeography of Population of North Eurasia Based on Mitochondrial DNA Variability Data, Magadan, NESC FEB RAS [In Russian].

Elson, J. L.; Turnbull, D. M.; Howell, N., 2004, Comparative Genomics and the Evolution of Human Mitochondrial DNA: Assessing the Effects of Selection, Am. J. Hum. Genet., 74, 229-238.

Eltsov, N. P.; Volodko, N. V.; Starikovskaya, E. B.; Mazunin, I. O.; Sukernik, R. I., 2010, The Role of Natural Selection in the Evolution of Mitochondrial Haplogroups in
Northeastern Eurasia, Russian Journal of Genetics, 46, 9, 1105-1107.

Fraumene, C.; Belle, E. M.; Castri, L.; Sanna, S.; Mancosu, G.; Cosso, M.; Marras, F.; Barbujani, G.; Pirastu, M.; Angius, A., 2006, High Resolution Analysis and Phylogenetic Network Construction Using Complete mtDNA Sequences in Sardinian Genetic Isolates, Mol. Biol. Evol., 23, 2101-2111.

Giles, R. E.; Blanc, H.; Cann, H. M.; Wallace, D. C., 1980, Maternal Inheritance of Human Mitochondrial DNA, Proc. Natl. Acad. Sci. USA, 77, 6715-6719.

Ingman, M.; Gyllensten, U., 2007, Rate Variation between Mitochondrial Domains and Adaptive Evolution in Humans, Hum. Mol. Genet., 16, 2281-2287.

Kivisild, T.; Shen, P.; Wall, D. P.; Do, B.; Sung, R.; Davis, K.; Passarino, G.; Underhill, P. A.; Scharfe, C.; Torroni, A.; Scozzari, R.; Modiano, D.; Coppa, A.; de 
Knijff, P.; Feldman, M.; Cavalli-Sforza, L. L.; Oefner, P. $J ., 2006$, The Role of Selection in the Evolution of Human Mitochondrial Genomes, Genetics, 172, 373-387.

Kovacevic-Grujicic, N.; Davidovic, S.; Malyarchuk, B., Aleksic, J.; Grzybowski, T.; Derenko, M.; Litvinov, A.; Stevanovic, M., 2018, Insights into the Mitochondrial Gene Pool of Serbian Population: Phylogenetic and Phylogeographic Analysis, Biologia Serbica, 40, 1 (Special Edition), 36.

Librado, P.; Rozas, J., 2009, DnaSP v5: A Software for Comprehensive Analysis of DNA Polymorphism Data, Bioinformatics, 25, 1451-1452.

Lipson, M.; Loh, P.-R.; Sankararaman, S., Patterson, N.; Berger, B.; Reich, D., 2015, Calibrating the Human Mutation Rate via Ancestral Recombination Density in Diploid Genomes, PLoS Genet., 11, e1005550.

Malyarchuk, B. A., 2011, Adaptive Evolution Signals in Mitochondrial Genes of Europeans, Biochemistry (Moscow), 76, 9, 702-706.

Malyarchuk, B.; Derenko, M.; Denisova, G.; Kravtsova, O., 2010, Mitogenomic Diversity in Tatars from the Volga-Urals Region of Russia, Mol. Biol. Evol., 27, 2220 2226.

Malyarchuk, B.; Derenko, M.; Denisova, G.; Litvinov, A.; Rogalla, U.; Skonieczna, K.; Grzybowski, T.; Pentelényi, K.; Molnár, M. J.; Guba, Z.; Zeke, T., 2018, Whole Mitochondrial Genome Diversity in Two Hungarian Populations, Molecular Genetics and Genomics, 293, 1255-1263.

Malyarchuk, B.; Litvinov, A.; Derenko, M.; Skonieczna, K.; Grzybowski, T.; Grosheva, A.; Shneider, Y.; Rychkov, S.; Zhukova, O., 2017, Mitogenomic Diversity in
Russians and Poles, Forensic Science International: Genetics, 30, 51-56.

Mishmar, D.; Ruiz-Pesini, E.; Golik, P.; Macaulay, V.; Clark, A. G.; Hosseini, S.; Brandon, M.; Easley, K.; Chen, E.; Brown, M. D.; Sukernik, R. I.; Olckers, A.; Wallace, D. C., 2003, Natural Selection Shaped Regional mtDNA Variation in Humans, Proc. Natl. Acad. Sci. USA, 100, 171-176.

Moilanen, J. S.; Finnila, S.; Majamaa, K., 2003, Lineage-Specific Selection in Human mtDNA: Lack of Polymorphisms in a Segment of MTND5 Gene in Haplogroup J., Mol. Biol. Evol., 20, 2132-2142.

Moilanen, J. S.; Majamaa, K., 2003, Phylogenetic Network and Physicochemical Properties of Nonsynonymous Mutations in the Protein-Coding Genes of Human Mitochondrial DNA, Ibid., 20, 1195-1210.

Nei, M.; Gojobori, T., 1986, Simple Methods for Estimating the Numbers of Synonymous and Nonsynonymous Nucleotide Substitutions, Ibid., 3, 418-426.

Ruiz-Pesini, E.; Mishmar, D.; Brandon, M.; Procaccio, V.; Wallace, D. C., 2004, Effects of Purifying and Adaptive Selection on Regional Variation in Human mtDNA, Science, 303, 223-226.

Soares, P.; Ermini, L.; Thomson, N.; Normina, M.; Rito, T.; Rohl, A.; Salas, A.; Oppenheimer, S.; Macaulay, V.; Richards, M. B., 2009, Correcting for Purifying Selection: An Improved Human Mitochondrial Molecular Clock, Am. J. Hum. Genet., 84, 740-759.

Stoljarova, M.; King, J. L.; Takahashi, M.; Aaspõllu, A.; Budowle, B., 2016, Whole Mitochondrial Genome Genetic Diversity in an Estonian Population Sample, Int. J. Legal Med., 130, 67-71. 